\title{
The Role of Mesolimbic Circuitry in Buffering Election-Related Distress
}

\author{
(D)Sarah M. Tashjian ${ }^{1}$ and Adriana Galván ${ }^{1,2}$ \\ 'Department of Psychology and ${ }^{2}$ Brain Research Institute, University of California, Los Angeles, Los Angeles, California 90095
}

The 2016 U.S. presidential election yielded distress among many individuals who identify with historically marginalized groups. We used functional magnetic resonance imaging and psychological measures to test the hypotheses that neural response to reward, probing the nucleus accumbens (NAcc) and medial prefrontal cortex (mPFC), and social support would ameliorate the effects of election distress among those who felt negatively affected by the result. Within 4 months of the 2016 U.S. presidential election, we tested human participants who felt affected by the election result $\left(n=40, M_{\text {age }}=21.9\right.$ years, 28 female) and control participants $\left(n=20, M_{\text {age }}=20.25\right.$ years, 12 female) who did not feel affected by the election result. Election-related distress significantly differed between the groups, and distress accounted for over half of the relationship between discrimination experiences and depression symptoms among affected individuals. NAcc activation, connectivity between the NAcc and $\mathrm{mPFC}$, and family support moderated the associations between election distress and depression symptoms. Prior work has primarily investigated mesolimbic circuitry in reward and motivation contexts, but our findings extend the relevance of functioning in this circuitry to ameliorating psychological manifestations of acute distress after shifts in political climate. These findings highlight the psychological effects of this important historic event and identify neurobiological and social mechanisms associated with individual differences in response to election distress.

Key words: depression; discrimination; distress; election; fMRI; nucleus accumbens

\section{Significance Statement}

The 2016 U.S. presidential election was psychologically distressing for many individuals. In this study, election-related distress was linked to depression symptomology for affected individuals but not control individuals. However, among individuals distressed by the election, those with greater neural response to reward and higher family support were protected against these depressive symptoms. Previous research has examined how neural response to reward after a discrete event ameliorates clinical symptoms. The current study extends this knowledge by demonstrating that both the brain and social support may play influential roles in dampening affective responses to ongoing and anticipated distress related to political climate. Leveraging this finding to enact interventions that dampen continuous distress, political or otherwise, is a promising endeavor for future research.

\section{Introduction}

The charged rhetoric of the 2016 U.S. presidential campaign left marginalized groups feeling vulnerable and victimized, with many reporting hopelessness, fear, and other symptoms commonly reported by those who have experienced a stressful event (Stoler, 2016; Gold, 2017). In the first $10 \mathrm{~d}$ after the election, the

\footnotetext{
Received Aug. 29, 2017; revised Jan. 2, 2018; accepted Jan. 16, 2018.

Author contributions:S.M.T. and A.G. designed research;S.M.T. and A.G. analyzed data; S.M.T. and A.G. wrote the paper.

This work was supported by the Jeffrey/Wenzel Chair in Behavioral Neuroscience to A.G. Preparation of this manuscript was supported in part by the National Science Foundation Graduate Fellowship to S.M.T.

The authors declare no competing financial interests.

Correspondence should be addressed to either Sarah M. Tashjian or Adriana Galván, Department of Psychology, University of California, 1285 Franz Hall, Los Angeles, CA 90095-1563, E-mail: smtashjian@ucla.edu or agalvan@ucla.edu.

DOI:10.1523/JNEUROSCI.2470-17.2018

Copyright $\odot 2018$ the authors $\quad 0270-6474 / 18 / 382887-12 \$ 15.00 / 0$
}

Southern Poverty Law Center (SPLC, 2016) recorded over 876 hate incidents, the outbreak of which SPLC attributed to the election. According to theories on discrimination (Comas-Díaz, 2016), distress may result from witnessing violence toward one's identity group or experiencing institutional discrimination. Perceived discrimination is linked to a variety of negative health outcomes including depression and psychological distress (Pascoe and Richman, 2009). Even individuals who have not been direct victims of postelection discrimination may have experienced distress through media coverage of hate crimes perpetrated against their identity groups (Gross, 2016; Reeves, 2016). Similarly, prior perceptions of discrimination may relate to the way vulnerable populations experienced these incidents. In contrast, for many the election result did not result in distress. In this study, we used functional magnetic resonance imaging (fMRI) and psychological measures to test differences in response to the election. We tested hypotheses that neural response to reward 
and social support would ameliorate the effects of election distress among those who felt negatively affected by the result.

Prior work primarily focuses on the role of the mesolimbic neural system, including the nucleus accumbens (NAcc) and medial prefrontal cortex (mPFC), in responding to reward and motivation. However, clinical and animal studies indicate these neural pathways are vulnerable to stressful experiences (Trainor, 2011; Ferenczi et al., 2016; Hanson et al., 2016). Greater activation in and stronger connectivity between the mPFC and NAcc have been associated with lower negative psychological symptoms in individuals with major depressive disorder (Furman et al., 2011; Young et al., 2016). Dampened mesolimbic responsivity to reward has been linked to individual differences in coping after stressful experiences (Feder et al., 2009; Nikolova et al., 2012; Admon et al., 2013). Although this work offers promising advances in understanding how neural circuitry buffers against negative outcomes, it remains unknown whether the election is associated with psychological distress and, if so, whether activity in reward-related neural circuitry is associated with ameliorated negative outcomes. We explore individual differences in neural responsivity as a phenotype of vulnerability to depression after a potentially distressing political event.

Social support is crucial to dampening negative psychological outcomes after stressful events (Schumm et al., 2006; Panagioti et al., 2014). High levels of social support have been associated with positive outcomes after traumatic events (Prati and Pietrantoni, 2009). Oxytocin facilitates social attachment by enhancing the reward value of social stimuli in the brain (Skuse and Gallagher, 2009) and may thus relate to openness to social support. Social support ameliorates negative psychological outcomes by operating on physiological and cognitive coping strategies, thereby enhancing resilience to stress (Eisenberger et al., 2007; Ozbay et al., 2007; Charuvastra and Cloitre, 2008; Marroquín, 2011). It has yet to be established whether social support can protect against deleterious effects of distressing shifts in political climate.

Within 4 months of the 2016 U.S. presidential election (November 2016 to March 2017), we tested a group of participants who reported feeling personally affected by the election result ("affected" group) and a group of participants who reported not feeling personally affected by the election ("control" group). We hypothesized that (1) the affected group would report greater election-related distress than the control group; (2) more discrimination experiences would relate to greater election distress and depression within the affected group; (3) within the affected group, election distress would relate to depression; and (4) greater neural activation and connectivity in response to reward and (5) greater social support from family and friends would moderate the relationship between election distress and depression. We tested both neural activation and social support as moderators, investigating two potential buffers against negative outcomes.

\section{Materials and Methods}

\section{Participants}

Sixty participants were tested after being deemed eligible to participate based on their responses to three prescreening questions: (1) Do you think the result of the 2016 U.S. presidential election will personally affect you?; (2) On a scale of 1 to $7,1=$ no negative emotional response and $7=$ an extremely negative emotional response, how do you feel about the result of the 2016 U.S. presidential election?; and (3) What do you identify as your gender, ethnicity, sexual orientation, religion, and immigration status? We used these prescreening questions before testing to ensure that we recruited a heterogeneous sample of participants inclusive of those who felt affected and unaffected by the election result. Before testing, participants were assigned to either the affected or the control group, and recruitment was terminated once the predetermined group sizes were obtained. Forty participants were assigned to the affected group (28 female; $M_{\text {age }}=20.25$ years; SD, 2.27; range, $18-28$ years). Participants were considered "affected" if they met three prescreening criteria: (1) they indicated they thought they would be personally affected by the election result, (2) they reported an affect rating of 5 or higher, and (3) they reported identifying with at least one historically marginalized group (Table 1). We also obtained free-response explanations of how participants thought they would be personally affected by the election result to ensure that our pretesting categorization as affected was accurate (Table 2). One additional affected participant was recruited but later excluded because of a technical error during scanning. Twenty participants were assigned to the control group ( 12 female; $M_{\text {age }}=21.90$ years; SD, 2.83; range, 18-30 years). Participants were considered "control" if they met two prescreening criteria: (1) they indicated they did not think they would be personally affected by the election result, and (2) they reported an affect rating of 4 or lower.

Our primary interest was to determine how individual differences in mesolimbic response to reward and social support buffered distress-related depression for affected participants. We recruited the control group as a comparison to (1) address that not all individuals felt distressed by the election, (2) demonstrate that election distress among affected participants was linked to depression but that this was not the case for the control group, and (3) assess whether there were underlying differences in the functioning of mesolimbic circuitry between the groups. Thus, we oversampled the affected group to investigate individual differences within that group rather than equally recruiting for both groups, which would have reduced power for within-group analyses.

We did not test a scale inclusive of positive affective responses because testing was conducted in a liberal urban city and conservative-leaning supporters may have experienced discrimination as a result of their political affiliation, conflating potential sources of distress in the two groups. In addition to the prescreening questions, eligibility criteria included fluency in English, between the ages of 18 and 30 years, and righthanded. Exclusion criteria included no prior developmental, psychiatric, or neurological disorder; no psychotropic medication; not claustrophobic; and no metal in the body.

\section{Experimental design}

Participants completed an MRI scan and self-report measures of electionrelated distress, everyday discrimination, depression symptoms, and perceived social support from family and friends. Only reports of distress were specifically framed with regard to the 2016 U.S. presidential election. Written consent was obtained in accordance with the university's Institutional Review Board, and participants were compensated for their participation. Testing sessions lasted $\sim 1.5 \mathrm{~h}$.

Self-report measures. Participants completed the Impact of Events Scale-Revised, a 22-item self-report measure that assesses subjective distress caused by traumatic events (Weiss, 2007). Participants were asked to respond to items on a five-point scale from 0 (not at all) to 4 (extremely) indicating for the past $7 \mathrm{~d}$ how distressing or bothersome each difficulty had been with respect to the 2016 U.S. presidential election (sample items: "I thought about it when I didn't mean to;" "Reminders of it caused me to have physical reactions, such as sweating, trouble breathing, nausea, or a pounding heart"). Total scores were used in analyses. The maximum possible score was 88 .

Participants completed the Everyday Discrimination Scale, a nineitem self-report measure of discrimination experiences (Williams et al., 1997). Participants were asked to respond to items on a scale from 0 (never) to 5 (almost every day) indicating how often each item occurs (sample items: "People act as if they are afraid of you," "You are called names or insulted"). Discrimination questions were not framed with regard to the election. Total scores were used in analyses. The maximum possible score was 45 .

Participants completed the Center for Epidemiological Studies Depression Scale (CES-D), a 20-item self-report measure that assesses depression symptoms as defined by the American Psychiatric Association Diagnostic and Statistical Manual (Radloff, 1977). Participants were asked to respond to items on a four-point scale from 0 (rarely or none of 
Table 1. Demographics

\begin{tabular}{|c|c|c|c|c|c|c|c|c|c|c|c|c|}
\hline & $\begin{array}{l}\text { Age } \\
\text { (years) }\end{array}$ & $\begin{array}{l}\% \text { of } \\
\text { sample }\end{array}$ & Gender & $\begin{array}{l}\% \text { of } \\
\text { sample }\end{array}$ & Ethnicity & $\begin{array}{l}\% \text { of } \\
\text { sample }\end{array}$ & $\begin{array}{l}\text { Sexual } \\
\text { orientation }\end{array}$ & $\begin{array}{l}\% \text { of } \\
\text { sample }\end{array}$ & Religion & $\begin{array}{l}\% \text { of } \\
\text { sample }\end{array}$ & $\begin{array}{l}\text { Political } \\
\text { affiliation }\end{array}$ & $\begin{array}{l}\% \text { of } \\
\text { sample }\end{array}$ \\
\hline \multirow[t]{11}{*}{ Demographics for the full sample $(n=60)$} & 18 & 15.0 & Female & 66.7 & Asian & 30.0 & Straight & 81.7 & Catholic & 25.0 & Democrat & 46.7 \\
\hline & 19 & 15.0 & Male & 33.3 & Hispanic/Latino & 26.7 & Bisexual & 8.3 & Christian & 23.3 & Republican & 3.3 \\
\hline & 20 & 31.7 & & & Caucasian & 21.7 & Gay & 3.3 & Agnostic & 20.0 & Independent & 8.3 \\
\hline & 21 & 6.7 & & & African American & 15.0 & Queer & 5.0 & Atheist & 16.7 & Libertarian & 1.7 \\
\hline & 22 & 16.7 & & & Middle Eastern & 6.7 & A-sexual & 1.7 & Hindu & 3.3 & Liberal & 8.3 \\
\hline & 23 & 3.3 & & & & & & & Islam & 3.3 & Conservative & 1.7 \\
\hline & 24 & 3.3 & & & & & & & Buddhist & 1.7 & None & 13.3 \\
\hline & 25 & 1.7 & & & & & & & Other & 6.7 & No response & 16.7 \\
\hline & 26 & 1.7 & & & & & & & & & & \\
\hline & 28 & 3.3 & & & & & & & & & & \\
\hline & 30 & 1.7 & & & & & & & & & & \\
\hline \multirow[t]{10}{*}{ Demographics for the control group $(n=20)$} & 18 & 5.0 & Female & 60.0 & Asian & 45.0 & Straight & 95.0 & Catholic & 20.0 & Democrat & 10.0 \\
\hline & 19 & 15.0 & Male & 40.0 & Hispanic/Latino & 10.0 & Bisexual & 5.0 & Christian & 35.0 & Republican & 10.0 \\
\hline & 20 & 15.0 & & & Caucasian & 35.0 & Gay & 0.0 & Agnostic & 15.0 & Independent & 15.0 \\
\hline & 21 & 10.0 & & & African American & 5.0 & Queer & 0.0 & Atheist & 15.0 & Libertarian & 5.0 \\
\hline & 22 & 25.0 & & & Middle Eastern & 5.0 & A-sexual & 0.0 & Hindu & 5.0 & Liberal & 15.0 \\
\hline & 23 & 10.0 & & & & & & & Islam & 0.0 & Conservative & 5.0 \\
\hline & 24 & 5.0 & & & & & & & Buddhist & 0.0 & None & 30.0 \\
\hline & 25 & 5.0 & & & & & & & Other & 10.0 & No response & 10.0 \\
\hline & 26 & 5.0 & & & & & & & & & & \\
\hline & 30 & 5.0 & & & & & & & & & & \\
\hline \multirow[t]{7}{*}{ Demographics for the affected group $(n=40)$} & 18 & 20.0 & Female & 70.0 & Asian & 22.5 & Straight & 75.0 & Catholic & 27.5 & Democrat & 65.0 \\
\hline & 19 & 15.0 & Male & 30.0 & Hispanic/Latino & 35.0 & Bisexual & 10.0 & Christian & 17.5 & Independent & 5.0 \\
\hline & 20 & 40.0 & & & Caucasian & 15.0 & Gay & 5.0 & Agnostic & 22.5 & Liberal & 5.0 \\
\hline & 21 & 5.0 & & & African American & 20.0 & Queer & 7.5 & Atheist & 17.5 & None & 5.0 \\
\hline & 22 & 12.5 & & & Middle Eastern & 7.5 & A-sexual & 2.5 & Hindu & 2.5 & No response & 20.0 \\
\hline & 24 & 2.5 & & & & & & & Islam & 5.0 & & \\
\hline & 28 & 5.0 & & & & & & & Buddhist & 2.5 & & \\
\hline
\end{tabular}

Table 2. Sample free-response explanations of how affected participants felt they would be affected by the 2016 U.S. presidential election

Affected participant explanations

I feel that people that have historically discriminated against minorities like me will feel safe in openly displaying their prejudice toward me and others.

I think I will be personally affected because I believe this president will only spread more racism and hate towards my people.

I will be mistreated in certain areas.

Since I am gay, I feel like hateful people will feel emboldened to discriminate against me.

Many of my family members are scared they will be deported. The overall social climate around me seems to have become more negative especially when it comes to immigration and equal rights. Although nothing racist has happened yet to me, I feel like the likelihood of something happening will increase these coming years.

As a person of color, I feel that this election has emboldened many to disregard, discriminate, and deny the experiences and realities of people like me. I fear for my life and my family's and my friends and friends' families lives.

My girlfriend and her family are undocumented, and I fear that the results of the U.S. presidential election will affect that status. As a Hispanic, I feel targeted as a minority by people who do not like my race.

My mother is undocumented and I have disabled relatives that rely on the Affordable Care Act that Trump is repealing, and I fear that my mom is going to be deported or experience more overt racism because she's undocumented.

As a woman, I feel that certain rights, such as the right to reproductive care, are being threatened. I am also the daughter of an immigrant and have had experience being racially profiled and feel that these events will only increase along the duration of Trump's presidency.

I am an African American woman, so this election will affect laws not only for my health rights but also create even more tension for minorities in everyday life.

With all that has happened lately, in regards to the "Muslim ban," I believe that legislation will be passed that enforces stronger immigration laws. Ultimately, I can see both of my parents being deported. This worries me a lot.

All explanations are reproduced verbatim.

the time) to 3 (most or all of the time) indicating for the past week how often they have felt or behaved in that way (sample items: "I did not feel like eating; my appetite was poor," "I talked less than usual"). CES-D questions were not framed with regard to the election. Total scores were used in analyses. The maximum possible score was 60.

Participants completed the Perceived Social Support (PSS) from Family and Friends Scale, which assessed perceived emotional support from family (20 items, PSS-Fa) and friends (20 items, PSS-Fr; Procidano and Heller, 1983). Participants were asked to respond to items with Yes, No, and Don't Know as to feelings or experiences they identify with (sample items: "My friends/family and I are very open about what we think about things," "My friends/family give(s) me the moral support I need"). PSS questions were not framed with regard to the election. Total scores were used in analyses. The maximum possible score for each scale was 20.

Participants also provided free-response explanations of how they thought they would be affected by the results of the 2016 U.S. presidential election to ensure that our categorization as affected was accurate from the participant's point of view. Example responses are listed in Table 2.

$f M R I$ paradigm. To probe neural activity in response to reward anticipation and feedback, participants completed a modified version of the Monetary Incentive Delay (MID) task (Knutson et al., 2000) while being scanned with fMRI (Fig. 1). The MID task has been widely used to elicit activation in reward circuitry. Participants received spoken and written instructions and completed a brief practice session outside of the scanner 


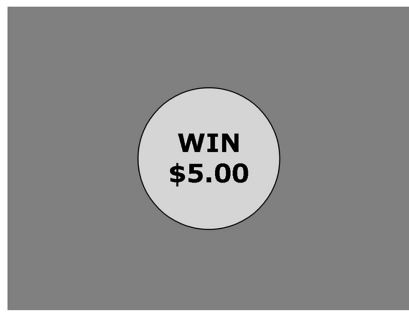

Anticipation

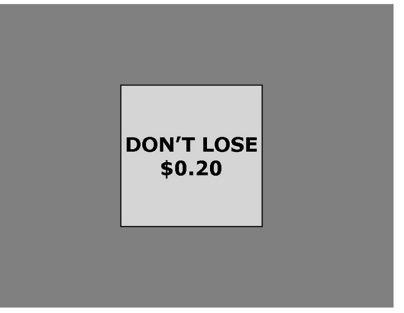

Anticipation

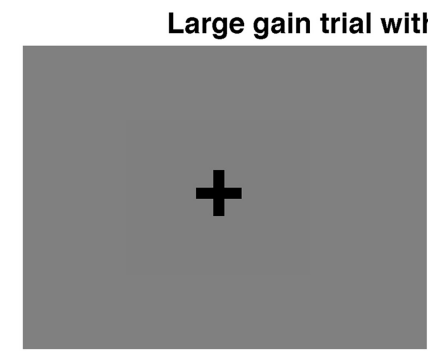

Fixation cross

Small loss trial with incorrect response

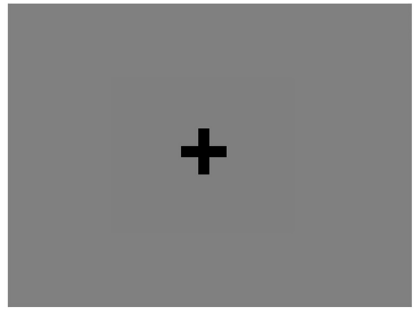

Fixation cross

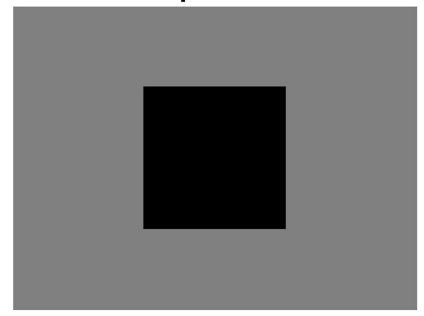

Target

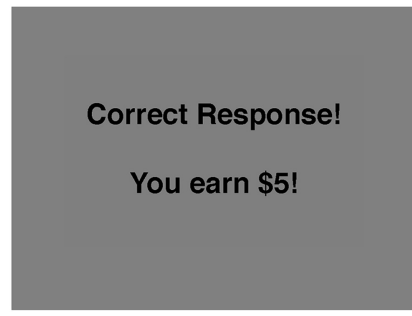

Feedback

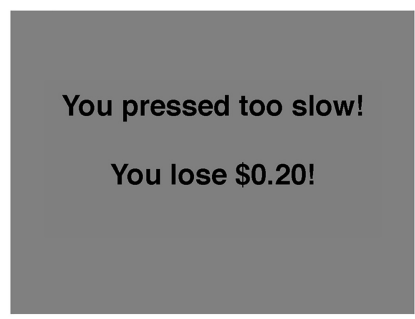

Feedback

Figure 1. Representative MID task trials. During each trial, participants first saw a cue indicating a potential gain or loss of different amounts (large, $\pm \$ 5.00 ;$ small, $\pm \$ 0.20$ ) or a cue indicating "no money at stake" (anticipation phase). Next, participants saw a jittered fixation cross as they waited for a rapidly presented target to which they were instructed to respond with a button press. Finally, participants saw the outcome of their action and their success at responding while the target was on the screen.

before beginning the experimental session. During each randomized event-related trial, participants viewed one of four types of monetary cues indicating a combination of incentive valence (gain, loss) and magnitude (large, $\pm \$ 5.00$; small, $\pm \$ 0.20$ ) or a cue indicating "no money at stake." Cues took one of three forms: a circle indicated a gain trial, a square indicated a loss trial, and a triangle indicated no money was at stake. Each cue was presented for $2000 \mathrm{~ms}$. Cue presentation was modeled as the anticipation phase of the task. Cues were followed by a fixation cross (jittered, 1500-4000 ms), after which a target of the same shape as the cue was rapidly presented on the screen $(150-500 \mathrm{~ms})$. If the participant pressed the button after the target onset but before the target offset, he or she either gained or avoided losing the cued amount of money. The hit rate was targeted at $60 \%$ for each participant by an algorithm that adaptively changed target durations every three trials based on past performance. The average reaction time from the practice session plus 2 SDs, with a maximum of $500 \mathrm{~ms}$, was used at the onset of the task for the purpose of target duration calculation. Feedback indicating the trial outcome was then presented. This feedback presentation was modeled as the feedback phase of the task. Potential trial outcomes were money gained (gain trials with a correct response), money not gained (gain trials with an incorrect response), money kept (loss trial with a correct response), money lost (loss trial with an incorrect response), and no money at stake (no money at stake trials with correct or incorrect response). Ten repetitions of each of the five trial types were presented in a randomized order for each individual, summing to a total of 50 trials in each run. Participants completed two functional runs, and each run lasted $5.33 \mathrm{~min}$.

fMRI data acquisition. The scan was conducted on a Siemens Magnetom Prisma MRI scanner with a 32-channel head coil. Parameters for image acquisition were as follows: voxel size, $2.4 \times 2.4 \times 2.4 \mathrm{~mm}$; slices, 60 ; slice thickness, $2.4 \mathrm{~mm}$; repetition time (TR), $800 \mathrm{~ms}$; echo time (TE), $30 \mathrm{~ms}$; flip angle, $52^{\circ}$; interleaved slice geometry; field of view (FoV), 216 $\mathrm{mm} ; 411$ volumes. Preprocessing was conducted using FEAT (FMRI Expert Analysis Tool) version 6.00, part of FSL (FMRIB Software Library, www.fmrib.ox.ac.uk/fsl; RRID:SCR_002823). Preprocessing consisted of nonbrain removal using BET (Brain Extraction Tool for FSL), high-pass filtering (100 s cutoff), and spatial smoothing using a Gaussian kernel of FWHM $5 \mathrm{~mm}$. Rigid body motion correction with $6 \mathrm{df}$ was performed using MCFLIRT (intra-modal motion correction tool based on optimization and registration techniques in FSL's registration tool FLIRT). A magnetization-prepared rapid-acquisition gradient echo (MPRAGE) scan was acquired for registration purposes (TR, $1900 \mathrm{~ms}$; TE, $2.26 \mathrm{~ms}$; FoV, $250 \mathrm{~mm}$; slice thickness, $1 \mathrm{~mm}$; 176 slices per slab). Each participant's functional data were registered to their MPRAGE using boundarybased registration (Greve and Fischl, 2009) and then to MNI (Montreal Neurological Institute) stereotaxic space with 12 degrees of freedom using FSL's registration method via FLIRT (FMRIB's Linear Image Registration Tool). Alignment was visually confirmed for all participants.

Data availability. Data, materials, and preregistration documents can be accessed at Open Science Framework.

\section{Statistical analysis}

At the individual level, one general linear model (GLM) was defined for each run of the MID task. The GLM included 10 multiple regressors for each event type: anticipation of gains, anticipation of losses, anticipation of no money at stake, feedback of gains, feedback of losses, feedback of no money at stake, feedback of no money gained, feedback of no money lost, all targets, and all fixation crosses. The magnitude of gains and losses was collapsed. Events were modeled with a canonical (double-gamma) hemodynamic response function for a duration from stimulus onset to stimulus offset. Temporal derivatives were included as covariates of no interest for all regressors, allowing a better fit for the whole model and reducing unexplained noise. Group-level analyses were performed using the FMRIB Local Analysis of Mixed Effects (FLAME-1) module in FSL (Beckmann et al., 2003). Outliers were de-weighted in the multisubject statistics using mixture modeling (Woolrich, 2008). Contrasts of interest were anticipation of gains versus losses and feedback of gains versus losses.

Based on previous meta-analytic findings (Knutson and Greer, 2008) and our a priori hypotheses, analyses focused on activity in two bilateral brain regions known to be activated in the MID task, the right and left NAcc and mPFC (Fig. 2). Consistent with prior work, regions of interest (ROIs) were specified as $8 \mathrm{~mm}^{3}$ diameter spheres centered on predicted foci derived from the meta-analysis in the Nacc $(x= \pm 10, y=10, z=$ $-2)$ and $\operatorname{mPFC}(x= \pm 5, y=45, z=0$; Wu et al., 2014). Foci are reported here as Talairach coordinates in conformity with the original metaanalysis and were converted to MNI coordinates using the icbm2tal transformation before analysis. Means of $\beta$-coefficients across the voxels of each ROI (bilateral Nacc, bilateral mPFC) were extracted and exported into SPSS (SPSS) and regressed against psychological variables of inter- 


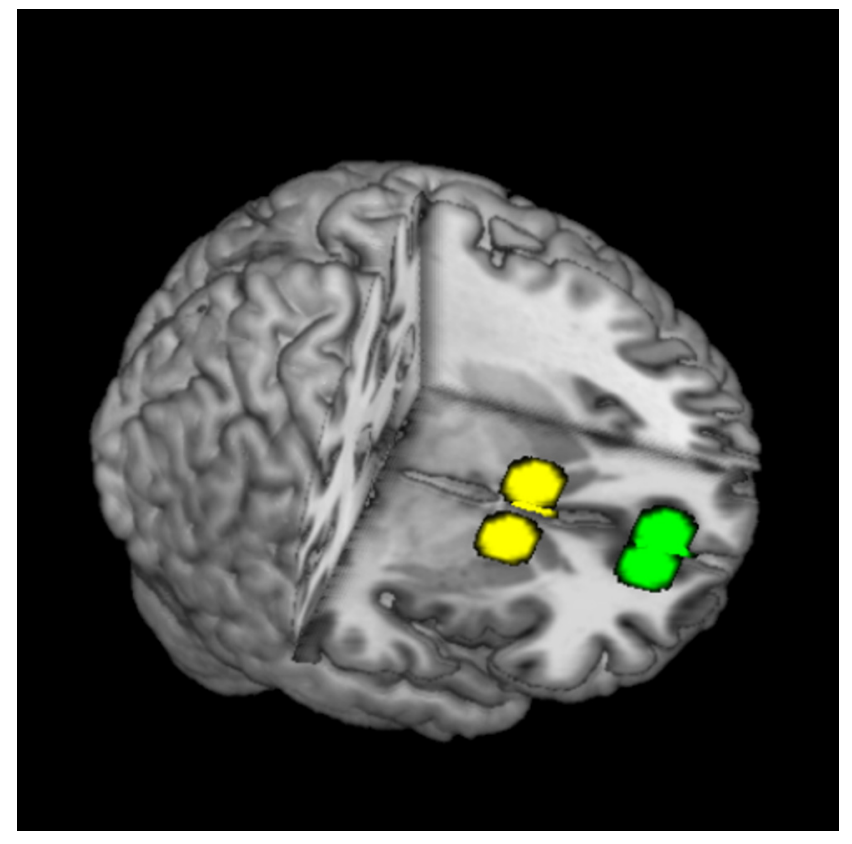

Figure 2. Bilateral $8 \mathrm{~mm}^{3} \mathrm{NAcc} \mathrm{ROI}$ (yellow, $x= \pm 10, y=10, z=-2$ ) and $\mathrm{mPFC}$ ROI (green, $x= \pm 5, y=45, z=0$ ) based on meta-analytic findings (Knutson and Greer, 2008).

est. The bilateral mPFC ROI was used for connectivity analyses. ROI approaches constrain the number of statistical tests, thus reducing probability of type I error, and provide greater sensitivity for detecting associations with self-report measures.

We also conducted psychophysiological interaction (PPI) analyses (Friston et al., 1997) to examine functional connectivity between the Nacc and mPFC. The standard-space bilateral Nacc mask was transformed to individual functional space using FLIRT, and the average time course of all voxels within the individual's mask was extracted using fslmeants. At the individual level, a GLM was defined for each run of the MID task with the same 10 multiple regressors from the ROI analyses. Additionally, the time series extracted from the bilateral Nacc mask (physical regressor) was added to each participant's individual-level GLM design matrix as well as the product between the Nacc time series (physical regressor) and the task contrast of interest (psychological regressor). The interaction term identified regions that covaried in a taskdependent manner with the Nacc. Two GLMs were defined separately for the contrast of (1) anticipation of gains minus anticipation of losses and (2) feedback of gains minus feedback of losses. The psychological regressor was zero-centered, and the physical regressor was demeaned. Two group-level analyses were performed (one for each contrast) using FLAME-1 in FSL with outliers de-weighted using mixture modeling. Means of $\beta$-coefficients across the voxels of the bilateral mPFC ROI for each subject, representing connectivity between the Nacc and MPFC, were extracted at the group level, exported into SPSS, and regressed against psychological variables of interest.

To analyze the relationship between discrimination, election distress, and depression, mediation (Model 4) was performed using Hayes' PROCESS macro for SPSS (Hayes, 2013). A completely standardized index of mediation $\left(\mathrm{ab}_{\mathrm{cs}}\right)$ was calculated for comparability with direct effects (Preacher and Kelley, 2011). To test the moderating effect of neural activation/connectivity and social support, moderated mediation (Model 14) was performed. Simple moderation (Model 1) was used to plot significant moderation effects with the low value of the moderator calculated as 1 SD below the mean and the high value calculated at $1 \mathrm{SD}$ above the mean, consistent with procedures outlined by Aiken and West (1991). Each analysis used a bootstrapping approach with 5000 samples, and significance was determined at $95 \%$ bias-corrected confidence intervals

\begin{tabular}{|c|c|c|}
\hline & \multicolumn{2}{|l|}{$M(S D)$} \\
\hline & Control & Affected \\
\hline Election affect & $2.70(1.17)$ & $6.23(0.80)$ \\
\hline Range & $1-4$ & $5-7$ \\
\hline Skew (SE) & -0.21 & -0.44 \\
\hline Election distress & $8.95(8.53)$ & $26.00(17.17)$ \\
\hline Range & $0-28$ & $3-77$ \\
\hline Skew (SE) & $1.24(0.51)$ & $1.32(0.37)$ \\
\hline Discrimination & $8.40(7.24)$ & 13.18 (7.76) \\
\hline Range & $0-29$ & $2-33$ \\
\hline Skew (SE) & $1.29(0.51)$ & $0.69(0.37)$ \\
\hline Depression symptoms & 7.85 (4.93) & $12.98(10.17)$ \\
\hline Range & $1-20$ & $0-50$ \\
\hline Skew (SE) & $1.12(0.51)$ & $1.48(0.37)$ \\
\hline PSS-family & $12.60(6.06)$ & $13.83(5.32)$ \\
\hline Range & $1-20$ & $1-20$ \\
\hline Skew (SE) & $-0.71(0.51)$ & $-0.77(0.37)$ \\
\hline PSS-friends & $14.95(5.75)$ & $16.98(3.87)$ \\
\hline Range & $3-20$ & $7-20$ \\
\hline Skew (SE) & $-1.19(0.51)$ & $-1.45(0.37)$ \\
\hline
\end{tabular}

(95\% BC CI). All variables were continuous and centered before analysis, and the estimated effects are reported as unstandardized regression coefficients. All analyses control for time from the election to testing. In all analyses, discrimination was the predictor variable, election-related distress was the mediator, and depression symptomology was the outcome variable. Nacc activation, Nacc-mPFC connectivity, and perceived social support (PSS-Fa, PSS-Fr) were tested as moderators.

\section{Results}

Affected and control participants significantly differed on age $\left(t_{(58)}=2.44 ; p=0.018 ; M_{\text {diff }}=1.65 ; 95 \% \mathrm{CI},[0.30,3.00]\right)$ and political affiliation $(0=$ Democrat/liberal, $1=$ not Democrat $/$ liberal; $t_{(48)}=5.27 ; p<0.001 ; M_{\text {diff }}=0.60 ; 95 \%$ CI, [0.37, $0.83])$ but not on gender $\left(0=\right.$ male, $1=$ female; $t_{(58)}=-0.77$; $p=0.45)$, ethnicity $\left(0=\right.$ Caucasian, $1=$ not Caucasian; $t_{(58)}=$ $-1.91 ; p=0.06)$, sexual orientation $(0=$ straight, $1=$ not straight; $\left.t_{(58)}=-1.99 ; p=0.05\right)$, or religion $(0=$ Christian/ Catholic, $1=$ not Christian/Catholic; $t_{(58)}=-0.36 ; p=0.72$; Table 1). Males and females did not differ on age $\left(t_{(58)}=0.85\right.$; $p=0.40)$, ethnicity $\left(0=\right.$ Caucasian, $1=$ not Caucasian; $t_{(58)}=$ 0.97; $p=0.34)$, sexual orientation $(0=$ straight, $1=$ not straight; $\left.t_{(58)}=0.23 ; p=0.82\right)$, religion $(0=$ Christian/Catholic, $1=$ not Christian/Catholic; $\left.t_{(58)}=-1.47 ; p=0.15\right)$, or political affiliation $(0=$ Democrat/liberal, $1=$ not Democrat $/$ liberal; $\left.t_{(48)}=1.65 ; p=0.11\right)$.

\section{Psychological outcomes}

Descriptive statistics for variables of interest are reported in Table 3. Supporting our first hypothesis, independent samples $t$ test revealed significant differences between the affected $(M=26.00)$ and control $(M=8.95)$ groups with regard to overall electionrelated distress $\left(t_{(58)}=-4.18 ; p<0.001 ; M_{\text {diff }}=-17.05 ; 95 \%\right.$ CI, $[-8.88,-25.22])$, such that affected individuals reported significantly greater election distress than control individuals. Affected participants reported significantly greater election distress than control participants for each of the intrusion, avoidance, and hyperarousal subscales. Election distress, as measured by the Impact of Events Scale, was not related to the prescreening affect rating demonstrating nuance in the manifestation of distress even among those who felt similarly negative about the election result. The groups also significantly differed with regard to discrimination $\left(t_{(58)}=-2.30 ; p=0.025 ; M_{\text {diff }}=-4.78 ; 95 \% \mathrm{CI}\right.$, 


\begin{tabular}{|c|c|c|c|c|c|c|c|}
\hline & 1 & 2 & 3 & 4 & 5 & 6 & 7 \\
\hline \multicolumn{8}{|c|}{ Bivariate correlations for the affected group ( $n=40)$} \\
\hline 1. Age & - & & & & & & \\
\hline 2. Election affect & $-0.36^{*}$ & - & & & & & \\
\hline 3. Election distress & -0.07 & 0.26 & - & & & & \\
\hline 4. Discrimination & 0.02 & -0.002 & $0.43^{* *}$ & - & & & \\
\hline 5. Depression symptoms & -0.11 & $0.36^{*}$ & $0.63^{* * *}$ & $0.51^{* *}$ & - & & \\
\hline 6. PSS-family & 0.10 & 0.05 & -0.13 & $-0.33^{*}$ & $-0.42^{* *}$ & - & \\
\hline 7. PSS-friends & 0.13 & -0.27 & 0.05 & -0.06 & -0.26 & $0.39^{*}$ & - \\
\hline \multicolumn{8}{|c|}{ Bivariate correlations for the control group $(n=20)$} \\
\hline 1. Age & - & & & & & & \\
\hline 2. Election affect & -0.41 & - & & & & & \\
\hline 3. Election distress & 0.00 & 0.36 & - & & & & \\
\hline 4. Discrimination & 0.36 & -0.36 & -0.02 & - & & & \\
\hline 5. Depression symptoms & 0.35 & -0.23 & 0.14 & 0.41 & - & & \\
\hline 6. PSS-family & $-0.65^{* *}$ & 0.40 & 0.03 & $-0.46^{*}$ & -0.32 & - & \\
\hline 7. PSS-friends & $-0.58^{* *}$ & 0.22 & -0.18 & $-0.63^{* *}$ & $-0.57^{* *}$ & $-0.68^{* *}$ & - \\
\hline
\end{tabular}

${ }^{*} p<0.05 ;{ }^{* *} p<0.01 ;{ }^{* * *} p<0.001$.

$[-8.94,-0.61])$, such that affected individuals $(M=13.18)$ reported significantly more everyday discrimination than control individuals $(M=8.40)$.

The groups differed as to depression symptoms $\left(t_{(58)}=-2.13 ; p=0.038 ; M_{\text {diff }}=\right.$ -5.13 ; $95 \% \mathrm{CI},[-9.95,-0.30])$, such that affected individuals $(M=12.98)$ reported significantly greater depressive symptoms than control individuals $(M=7.85)$. Using a recommended cutoff point of $\geq 20$ (Vilagut et al., 2016), one $(0.05 \%)$ control individual and nine $(22.5 \%)$ affected individuals reported clinical depression. Notably, and supporting our second and third hypotheses, election-related distress and discrimination were significantly correlated with depression symptoms only in the affected group (discrimination and depression: $r_{(40)}=0.51, p=0.001$; election distress and depression: $r_{(40)}=0.63, p<0.001$; Table 4).

\section{Discrimination, election distress, and depression}

To test whether, in the immediate aftermath of the election, electionrelated distress would mediate the association between discrimination experiences and depression, we conducted mediation analyses using PROCESS Model 4. Analyses included discrimination as the predictor, election-related distress as the mediator, and depression as the outcome and controlled for time since the election. For the affected group, results revealed that the indirect effect of discrimination on depression through election distress was significant $\left(R^{2}=0.50, F_{(3,36)}=11.84, p<0.001\right.$; indirect effect, 0.28; SE, 0.17; 95\% BC CI, [0.0538, 0.7702]; Fig. 3). The completely standardized index of mediation $\left(\mathrm{ab}_{\mathrm{cs}}=0.21\right)$ was 0.21 (SE, 0.01; 95\% BC CI, [0.0545, 0.4376]), 51\% the size of the remaining direct effect. In other words, over half of the association between discrimination and depression for the affected group was accounted for by election distress. Mediation was not significant in the control group $\left(R^{2}=0.10, F_{(3,16)}=1.34\right.$, $p=0.30$; indirect effect, -0.001 ; SE, $0.05 ; 95 \%$ BC CI, [ -0.1248 , $0.0993]$ ), so we did not test moderation in the control group.
Ventral striatal activation and election-related depression During the MID task, Nacc activation in response to feedback $\left(M_{\text {affected }}=11.39 ; M_{\text {control }}=8.16\right)$ did not significantly differ between groups $\left(t_{(58)}=-0.15 ; p=0.881 ; M_{\text {diff }}=-3.23 ; 95 \% \mathrm{CI}\right.$, [-46.32, 39.85]; Fig. $4 A)$. Nacc activation in response to anticipation $\left(M_{\text {affected }}=-3.24 ; M_{\text {control }}=8.32\right)$ did not significantly differ between groups $\left(t_{(58)}=1.02 ; p=0.310 ; M_{\text {diff }}=11.57 ; 95 \%\right.$ CI, $[-11.05,34.19])$.

To test our fourth hypothesis that Nacc activation would moderate depression related to election distress, we tested moderated mediation using PROCESS Model 14 in the affected group controlling for time from the election with discrimination as the predictor, election-related distress as the mediator, depression as the outcome, and Nacc activation during anticipation and feedback for the contrast of reward versus loss as moderators. Results revealed that moderated mediation was significant for Nacc activation during feedback of reward versus loss $\left(R^{2}=0.59, F_{(5,34)}=\right.$ 9.96, $p<0.001$; index of moderated mediation, -0.0033 ; SE, 0.002; 95\% BC CI, [ $-0.0085,-0.0006]$; Fig. 4B). Nacc activation significantly moderated the association between election distress and depression such that individuals with higher Nacc activation 

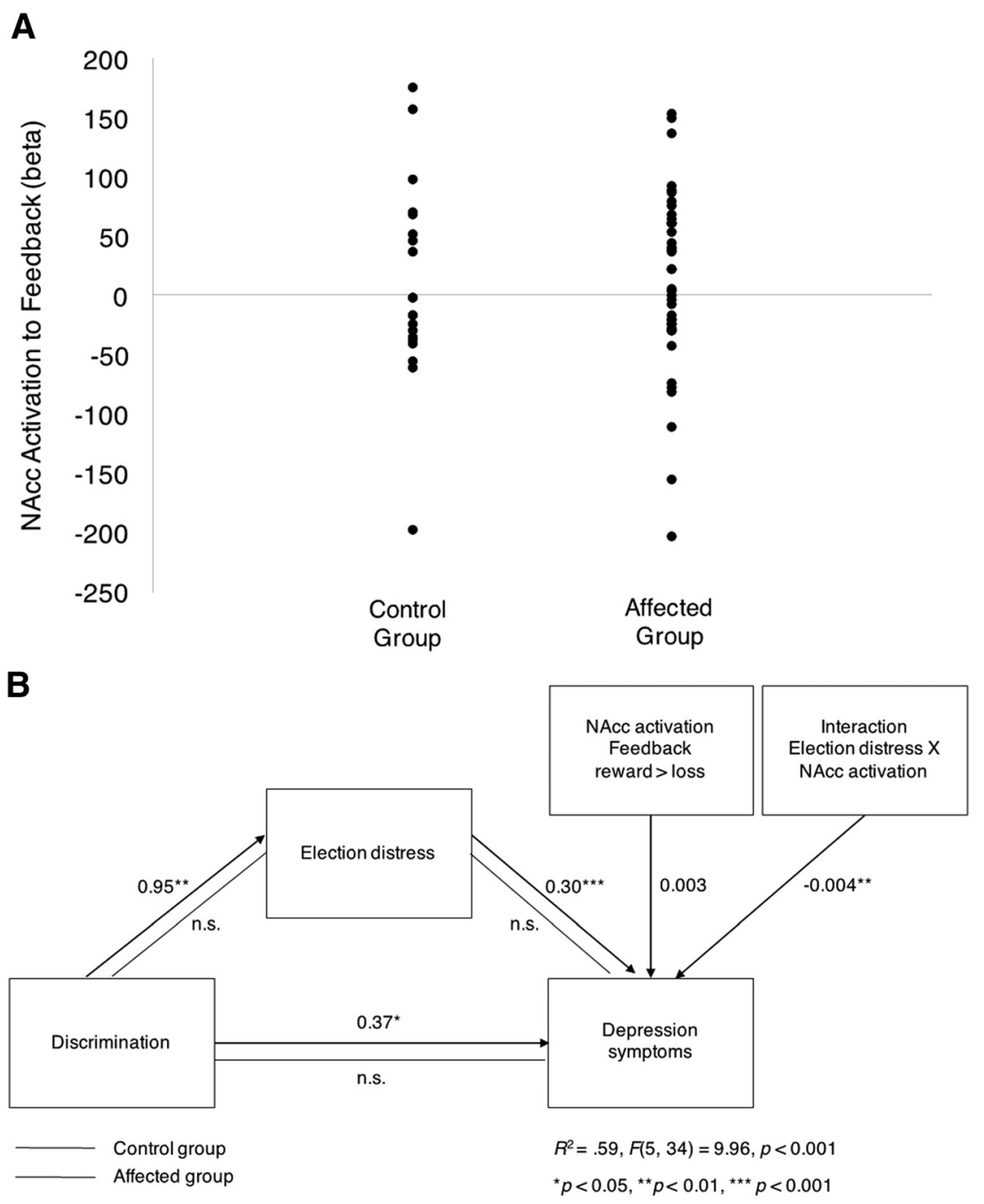

Controlling for time elapsed from the election to testing

\section{C}

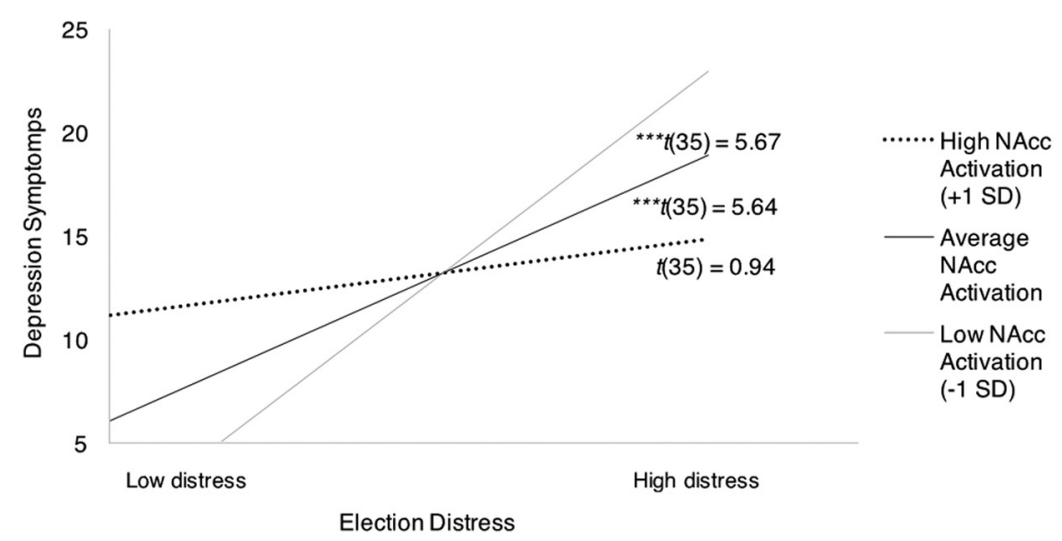

Figure 4. NAcc activation significantly moderated the link between election distress and depression symptoms for affected individuals. Analyses used a bootstrapping approach with 5000 samples, and significance was determined at $95 \%$ bias-corrected confidence intervals. All variables were continuous and centered before analysis, and the estimated effects are reported as unstandardized regression coefficients. $A$, Distribution by group of NAcc activation to feedback reward $>$ loss extracted from the bilateral NAcc ROI ( $x= \pm 10, y=10, z=-2,8 \mathrm{~mm}^{3}$ spheres). Neural activation did not differ by group. $\boldsymbol{B}$, Significant moderated mediation analysis. Election distress significantly mediated the relationship between discrimination and depression symptoms. NAcc activation significantly moderated the link between election distress and depression symptoms for affected individuals. C, Simple slope analyses showing that high NAcc activation ameliorated the relationship between election distress and depression symptoms for affected individuals. ${ }^{*} p<0.05,{ }^{* *} p<0.01,{ }^{* * *} p<0.001$. did not show a significant relationship between distress and depression but individuals with average or low Nacc did show a significant relationship (Fig. 4C). To assess whether this moderation was specific to the association between election distress and depression, we tested whether Nacc activation moderated the association between discrimination and election distress or the association between discrimination and depression, and neither of these paths were significant.

\section{Functional connectivity and election distress}

We conducted PPI analyses to examine whether functional coupling between the Nacc and mPFC moderated election-related depression for the affected group. Weaker connectivity in this circuitry has been identified as a potential phenotype of vulnerability to long-term negative outcomes after stressful life events (Sailer et al., 2008; Furman et al., 2011). Nacc-mPFC connectivity for anticipation of reward versus loss $\left(M_{\text {affected }}=0.002 ; M_{\text {control }}=0.03\right.$; $t_{(58)}=0.30 ; p=0.77 ; M_{\text {diff }}=0.03 ; 95 \%$ CI, $[-0.16,0.22])$ did not significantly differ between groups (Fig. 5A). NaccmPFC connectivity for feedback of reward $>$ loss also did not differ between groups $\left(M_{\text {affected }}=-0.030 ; M_{\text {control }}=\right.$ $-0.35 ; t_{(58)}=-1.41 ; p=0.16 ; M_{\text {diff }}=$ $-0.32 ; 95 \%$ CI, $[-0.78,0.13])$.

Confirming our fourth hypothesis, moderated mediation was significant for Nacc-mPFC connectivity during anticipation of reward versus loss $\left(R^{2}=0.58\right.$, $F_{(5,34)}=9.58, p<0.001$; index of moderated mediation, -0.48 ; SE, 0.35 ; $95 \% \mathrm{BC}$ CI, $[-1.2878,-0.0117]$; Fig. $5 B)$. Greater connectivity between the Nacc and $\mathrm{mPFC}$ during anticipation of rewards versus anticipation of losses significantly moderated the association between election distress and depression such that affected individuals showed a more attenuated relationship between distress and depression as connectivity strengthened (Fig. $5 C$ ). To assess whether this moderation was specific to the association between election distress and depression, we tested whether Nacc-mPFC connectivity moderated the association between discrimination and election distress or the association between discrimination and depression, and neither of these paths were significant.

\section{Post hoc fMRI analyses}

To disaggregate the contributions of reward and loss, we conducted post hoc moderation analyses (PROCESS Model 1) using the contrasts of reward versus no 

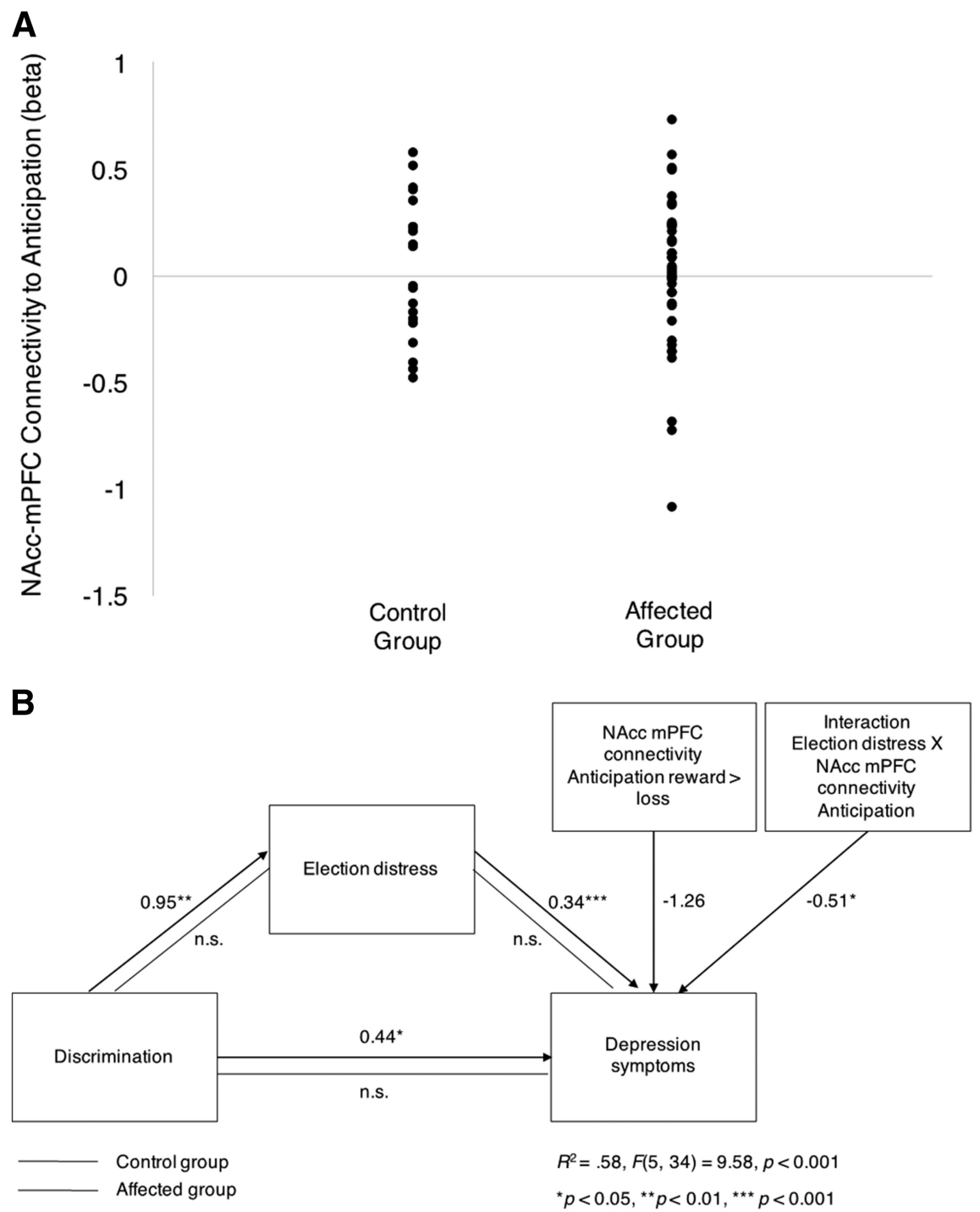

Controlling for time elapsed from the election to testing

\section{C}

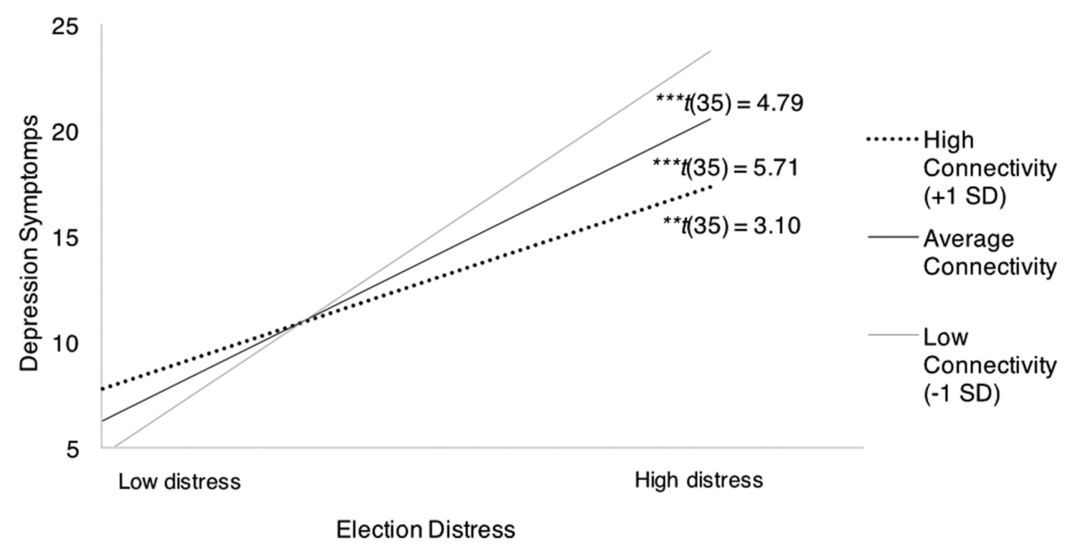

Figure 5. NAcc-mPFC connectivity significantly moderated links between election distress and depression symptoms for affected individuals. Analyses used a bootstrapping approach with 5000 samples, and significance was determined at $95 \%$ biascorrected confidence intervals. All variables were continuous and centered before analysis, and the estimated effects are reported as unstandardized regression coefficients. $\boldsymbol{A}$, Distribution by group of NAcc-mPFC connectivity to anticipation of reward $>$ loss from the bilateral mPFC ROI ( $x= \pm 5, y=45, z=0,8 \mathrm{~mm}^{3}$ spheres). Neural connectivity did not differ by group. $\boldsymbol{B}$, Significant moderated mediation analysis. Election distress significantly mediated the relationship between discrimination and depression symptoms. NAcc-mPFC connectivity significantly moderated links between election distress and depression money at stake and loss versus no money at stake for both NAcc activation and NAcc-mPFC connectivity. Moderation analyses, controlling for time from the election to testing, indicated that the association between election distress and depression was moderated by NAcc activation during feedback $\left(R^{2}=0.51\right.$, $\left.F_{(4,35)}=9.15, p<0.001\right)$, interaction $\left(B=-0.002 ; t_{(35)}=-2.13, p=0.04\right)$, and NAcc-mPFC connectivity during anticipation $\left(R^{2}=0.51, F_{(4,35)}=9.11, p<\right.$ $0.001)$, interaction $\left(B=-0.94, t_{(35)}=\right.$ $-2.24, p=0.03$ ) for the reward versus no money at stake contrast but not for loss versus no money at stake. Those with greater (+1 SD) NAcc activation during feedback to reward versus no money at stake did not show an association between election distress and depression, and those with greater (+1 SD) NAcc-mPFC connectivity during anticipation of reward versus no money at stake showed an attenuated association between election distress and depression. For the loss versus no money at stake contrasts, NAcc activation was not a significant moderator $\left(R^{2}=0.47, F_{(4,35)}=7.74, p<0.001\right.$; interaction: $B=-0.001, t_{(35)}=-1.13, p=$ $0.27)$, nor was NAcc-mPFC connectivity $\left(R^{2}=0.42, F_{(4,35)}=6.27, p<0.001\right.$; interaction: $\left.B=0.06, t_{(35)}=0.33, p=0.74\right)$.

Correlational analyses indicated that $\beta$ values for the feedback (NAcc activation) contrast of reward versus loss were positively correlated with reward versus no money at stake $\left(r_{(40)}=0.37, p=0.02\right)$ and negatively correlated with loss versus no money at stake $\left(r_{(40)}=-0.58, p<0.001\right)$. For the anticipation (NAcc-mPFC connectivity) contrast, betas for reward versus loss were positively correlated with reward versus no money at stake $\left(r_{(40)}=\right.$ $0.58, p<0.001)$ and (marginally significant) negatively correlated with loss versus no money at stake $\left(r_{(40)}=-0.29\right.$, $p=0.07)$.

\section{Social support and election distress}

To test our fifth hypothesis that perceptions of social support would moderate negative outcomes related to election distress, we tested moderated mediation for the affected group with family and friend support as moderators. Perceptions of family support

$\leftarrow$

symptoms for affected individuals. C, Simple slope analyses showing that high NAcc-mPFC connectivity ameliorated the relationship between election distress and depression symptoms for affected individuals. ${ }^{*} p<0.05$, ${ }^{* *} p<0.01$, ${ }^{* * *} p<0.001$ 

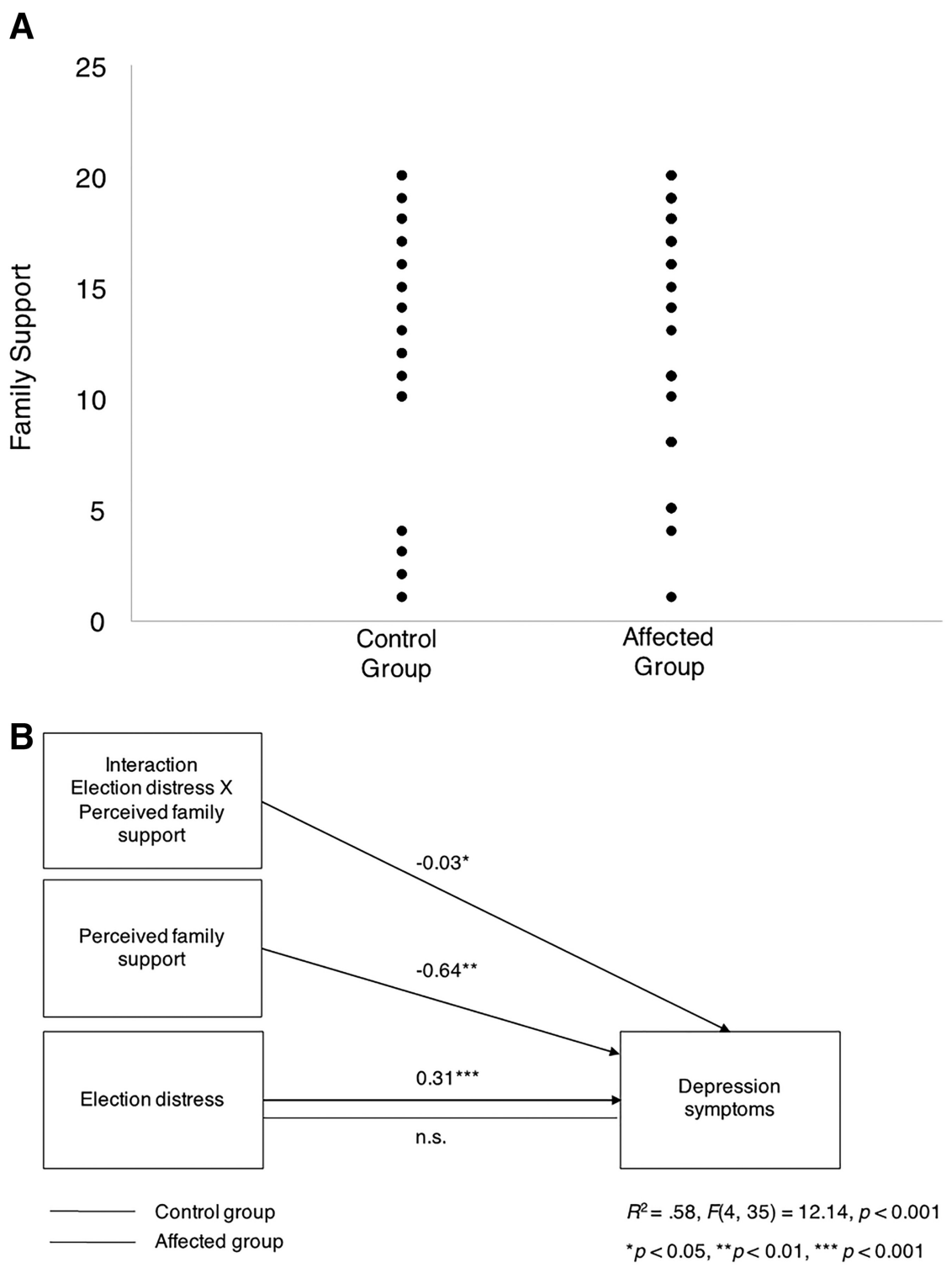

Controlling for time elapsed from the election to testing

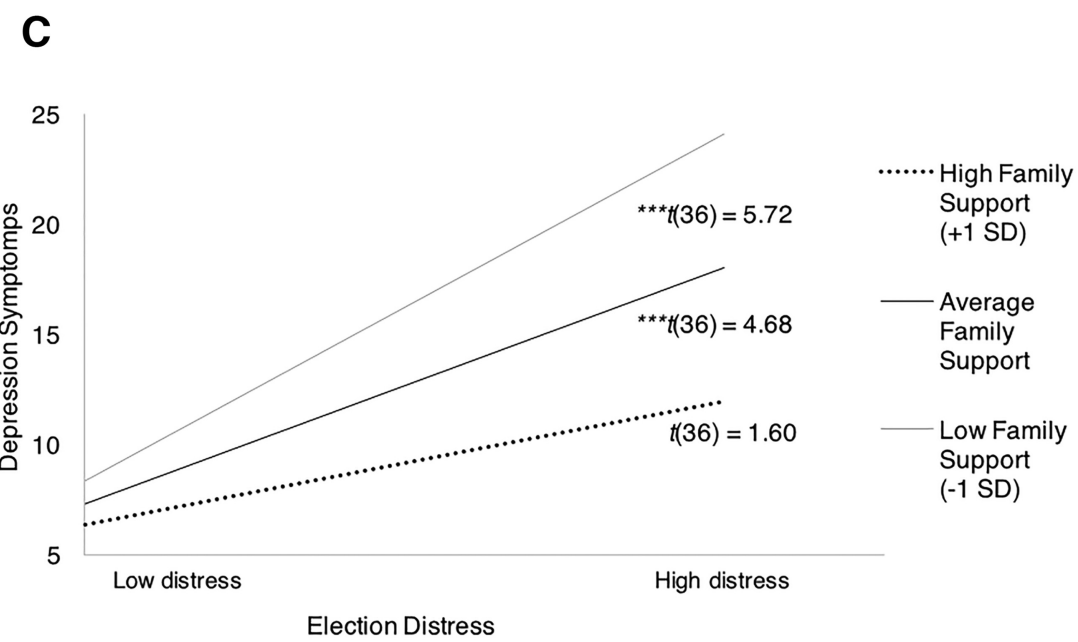

Figure 6. Family support significantly moderated links between election distress and depression symptoms for affected individuals. Analyses used a bootstrapping approach with 5000 samples, and significance was determined at $95 \%$ bias-corrected confidence intervals. All variables were continuous and centered before analysis, and the estimated effects are reported as unstandardized regression coefficients. $\boldsymbol{A}$, Distribution by group of family support. Family support did not differ by group.
$\left(M_{\text {affected }}=13.83 ; M_{\text {control }}=12.60\right) ; t_{(58)}=$ $-0.80 ; p=0.43 ; M_{\text {diff }}=-1.23 ; 95 \% \mathrm{CI}$, $[-4.28,1.83])$ support did not significantly differ between groups (Fig. 6A). Perceptions of friend support $\left(M_{\text {affected }}=\right.$ $16.98 ; M_{\text {control }}=14.95 ; t_{(58)}=-1.62 ; p=$ $0.11 ; M_{\text {diff }}=-2.03 ; 95 \%$ CI, [-4.53, $0.48]$ ) support did not significantly differ between groups. Family support and friend support were significantly correlated in both groups (Table 4). Family support and friend support were not correlated with $\mathrm{Nacc}$ activation or $\mathrm{Nacc}-$ mPFC connectivity.

Results revealed moderated mediation was not significant. However, simple moderation (PROCESS Model 1) demonstrated that family support significantly moderated the association between election distress and depression $\left(R^{2}=0.58\right.$; $F_{(4,35)}=12.14 ; p<0.001$; interaction, -0.03 ; SE, $0.01 ; t_{(35)}=-2.33 ; p=0.03$; Fig. $6 B$ ), such that individuals with higher family support did not show a significant relationship between distress and depression $\left(B=0.16 ; t_{(35)}=1.61 ; p=0.12\right)$, but individuals with average $B=0.31, t_{(35)}=$ $4.65, p<0.001$, or low family support did show a significant relationship $(B=0.46$; $t_{(35)}=5.67 ; p<0.001$; Fig. 6C). Perceptions of friend support did not significantly moderate the association between election distress and depression.

\section{Discussion}

The current findings elucidate reactivity of mesolimbic circuitry as an individual difference that explains variance in outcomes after distress related to the 2016 U.S. presidential election. For individuals who felt affected by the election, greater election distress was related to greater depression symptoms, but this association was not present for the control group. Election distress explained $51 \%$ of the association between perceived discrimination and depression, and activation and connectivity in frontostriatal circuitry moderated links between election distress and depression but not discrimination and psychological symptoms in the affected group. Greater activation in the NAcc and stronger connectivity between the NAcc and mPFC were associated with

$\leftarrow$

$\boldsymbol{B}$, Significant moderation analysis. Family support significantly moderated links between election distress and depression symptoms for affected individuals. C, Simple slope analyses showing that high family support ameliorated the relationship between election distress and depression symptoms for affected individuals. ${ }^{*} p<0.05$, ${ }^{* *} p<0.01$, *** $p<0.001$. 
less depression for affected individuals even under conditions of high election-related distress.

According to the Center for Disease Control, a traumatic event is when an event causes a lot of stress to the individual (https://www. cdc.gov/masstrauma/factsheets/public/coping.pdf). We did not clinically assess whether the 2016 U.S. presidential election manifested as a trauma for affected individuals. However, our results demonstrated links between election-related distress and depression, which has been commonly identified as psychological problems after trauma (https://www.cdc.gov/masstrauma/factsheets/ public/coping.pdf; Schumm et al., 2006). Additionally, we identified activity in neural circuitry related to reward and family support as moderators of these links. These moderators have been identified as sources of resiliency after trauma (Haden et al., 2007; Ozbay et al., 2007). Although political events are not typically characterized as traumatic, many of the concerns expressed by the affected participants in this study (Table 2) are similar to noted hallmarks of trauma (e.g., fear, helplessness). It is important to note that these indicators were only present for the affected group and that the control group evinced significantly less distress in response to the election as well as fewer depression symptoms compared with the affected group.

Only five $(12.5 \%)$ of the affected participants in our study reported personally experiencing election-related discrimination after the election (e.g., having people shout "build that wall" at them). However, 32 (80\%) of the affected participants reported concern for family, friends, and their community after the election (Table 2). These data provide evidence that individuals can experience distress and negative psychological outcomes related to witnessing or fearing discrimination against others with whom they identify (Comas-Díaz, 2016). Perceptions of everyday discrimination may also influence the way individuals internalize these vicarious experiences of discrimination against others. Our data suggest that in the immediate aftermath of the election, a large portion of the relationship between everyday discrimination experiences and depression was accounted for by election distress. This study expands existing literature to consider shared identity between direct victims and removed members of the same group and calls for treatment and intervention efforts to include not only those who directly experience discrimination but also those who identify with a targeted group.

\section{The role of mesolimbic circuitry on election-related distress}

Prior research has shown that that individual differences in the engagement of mesolimbic circuitry contribute to individual differences in psychological outcomes. We extend this research with the observation that this effect is similar after acute distress related to the election in a nonclinical population. What is particularly novel is the knowledge gained about ongoing distress that occurs on a population level across an important epoch in this country's history. For individuals who feel socially and politically marginalized, social support is powerful. By showing that social support and reward systems dampen depressive symptoms, this research highlights two powerful tools that can mitigate electionrelated distress. Unlike previous research on related questions, the affected individuals in our sample were not only reporting their distress from a past, discrete event but also their ongoing and future distress based on the perception that the event (the election) would personally affect them in the future. Alterations in the functioning of mesolimbic circuitry have been previously identified as a marker of vulnerability for clinical populations diagnosed with major depressive disorder (Furman et al., 2011; Young et al., 2016). Our data suggest that mesolimbic circuitry may be more protective against depressive symptoms in response to acute (i.e., election-related) versus chronic (i.e., discrimination-related) distress. Prior work on trauma and reward-related activation has not explored previous experiences of ongoing trauma like discrimination to disentangle the potentially distinct role that mesolimbic circuitry has in acute versus chronic trauma/distress. Although the current study is not positioned to definitively do so either, our findings may serve as a launching pad on which to pursue such questions.

Animal research provides a biological basis for the finding that reactivity in this circuitry has critical effects on behavioral manifestations of stress. Corticotropin-releasing factor (CRF) released in response to acute stressors acts on the NAcc to increase dopamine release, resulting in motivational behavior (Peciña et al., 2006). However, severe stress eliminates this effect such that CRF no longer produces appetitive responses to arousing stimuli (Lemos et al., 2012). This loss in regulation of motivational behavior after stress underlies anhedonia, which is a key symptom in major depressive disorder (Gorwood, 2008; American Psychiatric Association, 2013). Similarly, elevated biomarkers of inflammation in patients with major depressive disorder has been linked to decreased connectivity in frontostriatal circuitry, which in turn related to increased anhedonia (Felger et al., 2016).

\section{Social support moderates election distress and depression}

Perceived support from family also moderated the relationship between election distress and negative outcomes, supplementing prior work identifying family support as an important factor in healthy coping after distressing events (Kraaij et al., 2003; Oliva et al., 2009; Marroquín, 2011). Perceived support from friends was not a significant moderator for this sample, potentially identifying a more robust connection between family support and the mental health of young adults (Mattanah et al., 2011; Guassi-Moreira and Telzer, 2015). It is also possible that shared identity with family calls for greater reliance on family as opposed to friends in times of identity-related discrimination (Mulvaney-Day et al., 2007). Previous animal research indicates neurobiological factors such as oxytocin receptors in the NAcc in facilitating social attachment and reward experiences after positive social interactions (Insel and Shapiro, 1992; Dölen et al., 2013). Human neuroimaging studies have also shown greater ventral striatal activation when providing support to a loved one (Telzer et al., 2010; Inagaki and Eisenberger, 2012). However, indices of social support were not correlated with neural activation or connectivity in this sample, perhaps because of the nonsocial nature of the task used to elicit NAcc activation in this study. Our findings suggest that neurobiological and social resources may offer two distinct avenues of protection against deleterious psychological outcomes rather than accounting for divergent outcomes in the same resilient individuals. Notably, neural activation and perceptions of social support did not significantly differ for the affected and control groups. Rather than representing indices of pathology, these biological and social factors appear to represent sources of resilience for individuals experiencing election distress and related negative psychological symptoms.

\section{Limitations and future directions}

These findings should be considered in light of study limitations. We did not obtain measures of depression symptoms or discrimination experiences before the election, and thus we could not determine a causal pathway. However, past longitudinal work suggests poor mental health does not predict discrimination perceptions. No participants in this study reported prior diagnoses 
of psychological disorders, suggesting our results were not influenced by clinical symptoms before the election. Although we chose a time frame of 4 months after the election to capitalize on the immediate aftermath of the election results, it is possible that this time frame was too short to manifest between-group neural differences. A longitudinal study is needed to determine whether neural circuitry in affected individuals will demonstrate altered activation in response to continued election-related distress. We identified neural and social contributors of individual differences in psychological outcomes related to distressing events; however, election-related distress differed between the groups in our study and not all affected participants reported high distress. Future work should explore mechanisms that may lead to these different affective manifestations of common experiences.

\section{Conclusions}

Our findings elucidate pathways through which political events influence well-being, yielding insights into neural mechanisms contributing to individual differences in responses to distressing events in a nonclinical population. We demonstrate resiliency after distressing shifts in political climate for individuals who exhibit robust responsivity in the brain's reward circuitry. Our findings compliment animal research highlighting the vulnerability of the mesolimbic dopamine system to stressful experiences. We also provide empirical evidence of psychological manifestations of distress after shifts in political climate, which has implications for a vast number of individuals.

\section{References}

Admon R, Lubin G, Rosenblatt JD, Stern O, Kahn I, Assaf M, Hendler T (2013) Imbalanced neural responsivity to risk and reward indicates stress vulnerability in humans. Cereb Cortex 23:28-35. CrossRef Medline

Aiken LS, West SG (1991) Multiple regression: testing and interpreting interactions. Newbury Park, CA: Sage.

American Psychiatric Association (2013) Diagnostic and statistical manual of mental disorders. Ed 5. Arlington, VA: American Psychiatric Publishing.

Beckmann CF, Jenkinson M, Smith SM (2003) General multilevel linear modeling for group analysis in fMRI. Neuroimage 20:1052-1063. CrossRef Medline

Charuvastra A, Cloitre M (2008) Social bonds and posttraumatic stress disorder. Annu Rev Psychol 59:301-328. CrossRef Medline

Comas-Díaz L (2016) Racial trauma recovery: a race-informed therapeutic approach to racial wounds. In: The cost of racism for people of color: contextualizing experiences of discrimination. Cultural, racial, and ethnic psychology book series (Alvarez AN, Liang CTH, Neville HA, eds), pp 249-272. Washington, DC: APA.

Dölen G, Darvishzadeh A, Huang KW, Malenka RC (2013) Social reward requires coordinated activity of accumbens oxytocin and 5HT. Nature 501:179-184. CrossRef Medline

Eisenberger NI, Taylor SE, Gable SL, Hilmert CJ, Lieberman MD (2007) Neural pathways link social support to attenuated neuroendocrine stress responses. Neuroimage 35:1601-1612. CrossRef Medline

Feder A, Nestler EJ, Charney DS (2009) Psychobiology and molecular genetics of resilience. Nat Rev Neurosci 10:446-457. CrossRef Medline

Felger JC, Li Z, Haroon E, Woolwine BJ, Jung MY, Hu X, Miller AH (2016) Inflammation is associated with decreased functional connectivity within corticostriatal reward circuitry in depression. Mol Psychiatry 21: 13581365. CrossRef Medline

Ferenczi EA, Zalocusky KA, Liston C, Grosenick L, Warden MR, Amatya D, Katovich K, Mehta H, Patenaude B, Ramakrishnan C, Kalanithi P, Etkin A, Knutson B, Glover GH, Deisseroth K (2016) Prefrontal cortical regulation of brainwide circuit dynamics and reward-related behavior. Science 351:aac9698. CrossRef Medline

Friston KJ, Buechel C, Fink GR, Morris J, Rolls E, Dolan RJ (1997) Psychophysiological and modulatory interactions in neuroimaging. Neuroimage 6:218-229. CrossRef Medline

Furman DJ, Hamilton JP, Gotlib IH (2011) Frontostriatal functional connectivity in major depressive disorder. Biol Mood Anxiety Disord 1:11. CrossRef Medline
Gold J (2017) Post-election stress disorder' strikes on both sides. CNN (http://edition.cnn.com/2017/02/20/health/post-election-stress-partner/).

Gorwood P (2008) Neurobiological mechanisms of anhedonia. Dialogues Clin Neurosci 10:291-299. Medline

Greve DN, Fischl B (2009) Accurate and robust brain image alignment using boundary based registration. Neuroimage 48:63-72. CrossRef Medline

Gross N (2016) Are Americans experiencing collective trauma? New York Times (https://www.nytimes.com/2016/12/16/opinion/sunday/areamericans-experiencing-collective-trauma.html).

Guassi-Moreira JF, Telzer EH (2015) Changes in family cohesion and links to depression during the college transition. J Adolesc 43:72-82. CrossRef Medline

Haden SC, Scarpa A, Jones RT, Ollendick TH (2007) Posttraumatic stress disorder symptoms and injury: the moderating role of perceived social support and coping for young adults. Pers Individ Dif 42:1187-1198. CrossRef

Hanson JL, Albert D, Iselin AM, Carré JM, Dodge KA, Hariri AR (2016) Cumulative stress in childhood is associated with blunted reward-related brain activity in adulthood. Soc Cogn Affect Neurosci 11:405-412. CrossRef Medline

Hayes AF (2013) Introduction to mediation, moderation, and conditional process analysis. A regression-based approach. New York, NY: Guildford.

Inagaki TK, Eisenberger NI (2012) Neural correlates of giving support to a loved one. Psychosom Med 74:3-7. CrossRef Medline

Insel TR, Shapiro LE (1992) Oxytocin receptor distribution reflects social organization in monogamous and polygamous voles. Proc Natl Acad Sci U S A 89:5981-5985. CrossRef Medline

Knutson B, Greer SM (2008) Anticipatory affect: neural correlates and consequences for choice. Philos Trans R Soc Lond B Biol Sci 363:3771-3786. CrossRef Medline

Knutson B, Westdorp A, Kaiser E, Hommer D (2000) FMRI visualization of brain activity during a monetary incentive delay task. Neuroimage 12:20 27. CrossRef Medline

Kraaij V, Garnefski N, de Wilde EJ, Dijkstra A, Gebhardt W, Maes S, ter Doest L (2003) Negative life events and depressive symptoms in late adolescence: bonding and cognitive coping as vulnerability factors? J Youth Adolesc 32: 185-193. CrossRef

Lemos JC, Wanat MJ, Smith JS, Reyes BA, Hollon NG, Van Bockstaele EJ, Chavkin C, Phillips PE (2012) Severe stress switches CRF action in the nucleus accumbens from appetitive to aversive. Nature 490:402-406. CrossRef Medline

Marroquín B (2011) Interpersonal emotion regulation as a mechanism of social support in depression. Clin Psychol Rev 31:1276-1290. CrossRef Medline

Mattanah JF, Lopez FG, Govern JM (2011) The contributions of parental attachment bonds to college student development and adjustment: a meta-analytic review. J Couns Psychol 58:565-596. CrossRef Medline

Mulvaney-Day NE, Alegría M, Sribney W (2007) Social cohesion, social support, and health among Latinos in the United States. Soc Sci Med 64:477-495. CrossRef Medline

Nikolova YS, Bogdan R, Brigidi BD, Hariri AR (2012) Ventral striatum reactivity to reward and recent life stress interact to predict positive affect. Biol Psychiatry 72:157-163. CrossRef Medline

Oliva A, Jimenez JM, Parra A (2009) Protective effect of supportive family relationships and the influence of stressful life events on adolescent adjustment. Anxiety Stress Coping 22:137-152. CrossRef Medline

Ozbay F, Johnson DC, Dimoulas E, Morgan CA, Charney D, Southwick S (2007) Social support and resilience to stress. Psychiatry 4:35-40. Medline

Panagioti M, Gooding PA, Taylor PJ, Tarrier N (2014) Perceived social support buffers the impact of PTSD symptoms on suicidal behavior: implications into suicide resilience research. Compr Psychiatry 55:104-112. CrossRef Medline

Pascoe EA, Smart Richman L (2009) Perceived discrimination and health: a meta-analytic review. Psychol Bull 135:531-554. CrossRef Medline

Peciña S, Schulkin J, Berridge KC (2006) Nucleus accumbens corticotropinreleasing factor increases cue-triggered motivation for sucrose reward: paradoxical positive incentive effects in stress? BMC Biol 4:8. CrossRef Medline

Prati G, Pietrantoni L (2009) Optimism, social support, and coping strategies as factors contributing to posttraumatic growth: a meta-analysis. J Loss Trauma 14:364-388. CrossRef

Preacher KJ, Kelley K (2011) Effect size measures for mediation models: 
quantitative strategies for communicating indirect effects. Psychol Methods 16:93-115. CrossRef Medline

Procidano ME, Heller K (1983) Measures of perceived social support from friends and from family: three validation studies. Am J Community Psychol 11:1-24. CrossRef Medline

Radloff LS (1977) The CES-D scale: a self report depression scale for research in the general population. Appl Psychol Meas 1:385-401. CrossRef

Reeves J (2016) Many minorities frightened of what a Trump presidency means for them. PBS Newshour (http://www.pbs.org/newshour/rundown/ many-minorities-frightened-trump-presidency-means/).

Sailer U, Robinson S, Fischmeister FP, König D, Oppenauer C, LuegerSchuster B, Moser E, Kryspin-Exner I, Bauer H (2008) Altered reward processing in the nucleus accumbens and mesial prefrontal cortex of patients with posttraumatic stress disorder. Neuropsychologia 46:28362844. CrossRef Medline

Schumm JA, Briggs-Phillips M, Hobfoll SE (2006) Cumulative interpersonal traumas and social support as risk and resiliency factors in predicting PTSD and depression among inner-city women. J Trauma Stress 19: 825-836. CrossRef Medline

Skuse DH, Gallagher L (2009) Dopaminergic-neuropeptide interactions in the social brain. Trends Cogn Sci 13:27-35. CrossRef Medline

Southern Poverty Law Center (2016) Ten days after: harassment and intimidation in the aftermath of the election. Southern Poverty Law Center (https://www. splcenter.org/sites/default/files/com_hate_incidents_report_final.pdf).

Stoler DR (2016) Post election anxiety and depression. Psychology Today (https://www.psychologytoday.com/blog/the-resilient-brain/201612/postelection- anxiety-and-depression).
Telzer EH, Masten CL, Berkman ET, Lieberman MD, Fuligni AJ (2010) Gaining while giving: an fMRI study of the rewards of family assistance among white and Latino youth. Soc Neurosci 5:508-518. CrossRef Medline

Trainor BC (2011) Stress responses and the mesolimbic dopamine system: social contexts and sex differences. Horm Behav 60:457-469. CrossRef Medline

Vilagut G, Forero CG, Barbaglia G, Alonso J (2016) Screening for depression in the general population with the Center for Epidemiologic Studies Depression (CES-D): a systematic review with meta-analysis. PLoS One 11: e0155431. CrossRef Medline

Weiss DS (2007) The Impact of Events Scale-Revised. In: Assessing psychological trauma and PTSD: a practitioner's handbook, Ed 2 (Wilson JP, Keane M, eds), pp 168-189. New York, NY: Guilford.

Williams DR, Yan Yu, Jackson JS, Anderson NB (1997) Racial differences in physical and mental health: socioeconomic status, stress, and discrimination. J Health Psychol 2:335-351. CrossRef Medline

Woolrich M (2008) Robust group analysis using outlier inference. Neuroimage 41:286-301. CrossRef Medline

Wu CC, Samanez-Larkin GR, Katovich K, Knutson B (2014) Affective traits link to reliable neural markers of incentive anticipation. Neuroimage 84 : 279-289. CrossRef Medline

Young CB, Chen T, Nusslock R, Keller J, Schatzberg AF, Menon V (2016) Anhedonia and general distress show dissociable ventromedial prefrontal cortex connectivity in major depressive disorder. Transl Psychiatry 6:e810. CrossRef Medline 